\title{
Calculation of Economic Dispatch of Power System Based on Improved Particle Swarm Optimization Algorithm Abstract
}

\author{
Xia Fei, Xia Zongze, Huang Xiaobo, Huang Xing \\ State Grid Liaoyang Electric Power Supply Company, Liaoning, China
}

\begin{abstract}
Keywords: Electric power system, Economic dispatch, Particle swarm optimization, System
\end{abstract} simulation

\begin{abstract}
For the power system economic dispatch problem, this paper takes the power system generation fuel cost as the objective function, and take into account the net loss of the power system. At the same time, it neglects the valve point effect in the process of the generation and establish power system model to meet the running power balance constraints and the motor running In this paper, the IEEE30BUS power system is chosen as an example, and this paper uses the improved particle swarm optimization algorithm to simulate the power system of the known fuel consumption parameters, and the simulation result is compared with the optimization results of the basic particle swarm optimization algorithm. The result of system simulation is: the optimization result of the traditional particle swarm optimization is that the total power is $1375.63 \mathrm{MW}$, the net loss is $11.89 \mathrm{MW}$ and the total cost is $16562.98(\$ / \mathrm{h})$; The optimization results obtained by the improved particle swarm optimization algorithm are that the total power is $1375.08 \mathrm{MW}$, the net loss is $10.49 \mathrm{MW}$, the total cost is $16546.86(\$ / \mathrm{h})$. The net loss of the improved algorithm is reduced by $2 \%$ compared with the traditional algorithm and the total cost is reduced by $6.12(\$ / \mathrm{h})$. The simulation results show that the improved particle swarm optimization algorithm can effectively solve the power system economic dispatch calculation problem.
\end{abstract}

\section{INTRODUCITION}

The economic dispatch of power system has been a hot research topic of the experts and scholars. It is an important subject of power system operation [1]. The main purpose of the research is to make the operation cost of the generating unit is the smallest under the condition of meeting the load demand and so on [2]. In electric power system, there are many factors that need to be considered in the operation of generating units, such as system operation, system stability and so on. So the power system economic dispatch problem is a high dimension, nonlinear and multi constrained optimization problem.

Electric power system economic dispatch plays an important role in the whole power system operation and control [3, 4]. It belongs to the category of power system planning and operation scheduling. It is a kind of typical optimization problem, that is to say,, in order to ensure the system load and security and stability, it can use the existing resources effectively and realize the system running cost minimization [5]. The study of economic dispatch of power system can be traced back to the 30's of last century, and from the beginning of this century 90 times, with the rapid progress of power technology, the international electricity market also will be vigorously developed, which put forward higher requirements for electric power system [6]. The power system economic dispatch research has become particularly important. In recent years, many experts and scholars at home and abroad have devoted themselves to the study of economic dispatch of electric power system, trying to find a better solution to obtain more economic benefits.

In this paper, the economic performance of the power system is optimized under the premise of meeting the reliable power supply and power quality. 


\section{IMPROVED PARTICLE SWARM ALGORITHM TO SOLVE POWER SYSTEM ECONOMIC OPERATION}

In this chapter, we introduce an improved particle swarm optimization algorithm, and we build the model of the target to reduce the total generation cost of the system, and the improved particle swarm optimization algorithm is applied to the economic dispatch of power system, and it is proved that the improved PSO algorithm is more effective.

\subsection{Power system economic dispatch model}

Power system economic dispatch model can be described as:

$$
\min F_{T}=\sum_{i=1}^{N_{G}} F_{i}\left(P_{G i}\right)=\sum_{i}^{N_{G}}\left(a_{i} P_{G i}^{2}+b_{i} P_{G}+c_{i}\right)
$$

In the above formula: $F_{T}$ is the total fuel cost of the system $(\$ / \mathrm{h}) ; \mathrm{Fi}\left(\mathrm{P}_{\mathrm{Gi}}\right)$ is the fuel consumption of the B generator in the system $(\$ / h) ; N_{G}$ is the total number of the generators in the system; $\mathrm{P}_{\mathrm{Gi}}$ is the active power output of the $\mathrm{i}$ generator in the system (MW); $\mathrm{a}_{\mathrm{i}}, \mathrm{b}_{\mathrm{i}}$ and $\mathrm{c}_{\mathrm{i}}$ are the cost parameters of the system of the i generator, and their value is constant [7].

In the study of economic dispatch of power system, there are two main constraint conditions usually need to be considered: namely the power balance and motor operating constraints.

Power system active power balance constraints can be described as:

$$
\sum_{i=1}^{N} P_{G i}=P_{\text {load }}+P_{\text {loss }}
$$

In the above formula: $\mathrm{P}_{\text {load }}$ is the total load of the power system; $\mathrm{P}_{\text {loss }}$ is the net loss of the power system; the $\mathrm{P}_{\mathrm{Gi}}$ is the power of the $\mathrm{i}$ generator.

Generator running constraints can be described as:

$$
P_{G i \min } \leq P_{G i} \leq P_{G i \max }
$$

In the above formula: $\mathrm{P}_{\text {Gimin }}$ and $\mathrm{P}_{\text {Gimax }}$ are the upper and lower bounds for the active power of the generator.

When the B coefficient method is used, the relationship between the net loss and the active power of the generator is:

$$
P_{\text {Loss }}(P, T)=\sum_{i=1}^{N_{G}} \sum_{j=1}^{N_{G}} P_{G i}(t) B_{i j} P_{G i}(y)+\sum_{i}^{N_{G}} P_{G i}(t) B_{o i}+B_{o o}
$$

In the above formula: $\mathrm{P}_{\text {Loss }}(\mathrm{P}, \mathrm{T})$ is the total loss of the system; $\mathrm{B}_{\mathrm{ij}}, \mathrm{B}_{\mathrm{io}}$ and $\mathrm{B}_{\text {og }}$ are the loss coefficient of the system. In the practical application, we can measure the $\mathrm{B}$ coefficient at regular intervals according to the actual situation.

\subsection{Improved particle swarm optimization algorithm}

The basic particle swarm optimization algorithm in the process of evolution is to update the speed of particle motion by tracking the optimal solution which is found by it so far, and then update the location by updating the speed. From another point of view, the particle can learn from the successful experience of its own and the whole group, so as to guide the next step of the action strategy. But sometimes it can also get useful information from some of the examples of failure, by summing up the lessons of the past; you can get a favorable experience for future development. Such a learning strategy can also be used when the particle swarm evolves [8, 9].

Based on this, this paper adopts a new particle swarm optimization algorithm, which is a dynamic double population particle swarm optimization algorithm (DDPSO). The evolutionary strategy used in dynamic double population particle swarm optimization is not only to learn from the successful experience but also to obtain useful information from the previous examples of failure to update the speed and location of the particles. In the process of the whole iterative optimization, the particle can be expressed as the particle itself or the position of the poor fitness value of the particle, Assuming that the worst position of the i particle to date is $i_{s}=\left(s_{i 1}, s_{i 2}, \ldots . . s_{\text {in }}\right)$, and the optimal location of the whole particle swarm searching in the process of iterative optimization is $s_{a g}=\left(s_{g 1}, s_{g 2}, \ldots . . . s_{i g n}\right)$, then you can get the speed and position of the i particle 
update formula.

$$
\begin{aligned}
& v_{i d}^{k+1}=w v v_{i d}^{k}+c_{1} r_{1}\left(x_{i d}^{k}-x_{i d}^{k}\right)+c_{2} r_{2}\left(x_{i d}^{k}-x_{i d}^{k}\right) \\
& x_{i d}^{k+1}=x_{i d}^{k}+v_{i d}^{k+1}
\end{aligned}
$$

If the particle is updated only in only in the way that the above formula is provided, which is clearly not in conformity with the actual experience. In addition to acquiring experience from the failure, more is to obtain useful information from some successful examples; the information obtained from the failure of the experience is relatively small. In this paper, the dynamic double population particle swarm optimization algorithm can not only get information from the failure experience, but also can be obtained from the experience of success, and then we can combine the experience of the two to update the particle.

\subsection{System simulation}

In this paper, the IEEE30BUS node system is used as an example. The system contains 6 units, and the total load of the system is 1263MW, the total power cost of the system and the system's net loss can be calculated by the formula (1) and formula (2).

The parameters of the power system power consumption are shown in table 1 .

Table 1 System of fuel consumption parameters and power limit

\begin{tabular}{|c|l|l|l|l|l|}
\hline $\begin{array}{c}\text { Unit } \\
\text { number }\end{array}$ & $\mathrm{a}_{\text {ir }}$ & $\mathrm{b}_{\mathrm{i}}$ & $\mathrm{c}_{\mathrm{i}}$ & $\mathrm{P}_{\text {riming }}$ & $\mathrm{P}_{\text {rime }}$ \\
\hline 1 & 0.0060 & 6.9 & 250 & 90 & 600 \\
\hline 2 & 0.0084 & 9.8 & 210 & 40 & 400 \\
\hline 3 & 0.0079 & 7.9 & 230 & 70 & 300 \\
\hline 4 & 0.0079 & 10.9 & 200 & 40 & 200 \\
\hline 5 & 0.0069 & 9.5 & 220 & 40 & 250 \\
\hline
\end{tabular}

\section{EXPERIMENTAL RESULTS AND ANALYSIS,}

Through multiple simulations, the power output of the IEEE30BUS power system and the total power generation cost can be obtained. The optimization results are shown in Table 2.

Table 2 Generator power output and total generation cost of IEEE30 power system

\begin{tabular}{|l|l|l|}
\hline Output power(MW) & PSO & DDPSO \\
\hline P1 & 445.46 & 444.95 \\
\hline P1 & 210.00 & 200.47 \\
\hline P1 & 248.98 & 246.62 \\
\hline P1 & 150.10 & 148.99 \\
\hline P1 & 175.76 & 174.59 \\
\hline P1 & 77.87 & 79.10 \\
\hline Total power & 1375.63 & 1375.08 \\
\hline Net loss $P_{\text {lods }}(\$ / h)$ & 11.89 & 10.49 \\
\hline All-in cost & 1662.98 & 16556.86 \\
\hline
\end{tabular}

The results of Table 2 show that the optimization result of the traditional particle swarm optimization is that the total power is $1375.63 \mathrm{MW}$, the net loss is $11.89 \mathrm{MW}$ and the total cost is 16562.98 ( $\$ / \mathrm{h}$ ); The optimization results obtained by the improved particle swarm optimization algorithm are that the total power is $1375.08 \mathrm{MW}$, the net loss is $10.49 \mathrm{MW}$, the total cost is $16546.86(\$ / \mathrm{h})$. The net loss of the improved algorithm is reduced by $2 \%$ compared with the traditional algorithm and the total cost is reduced by $6.12(\$ / \mathrm{h})$, which shows that the improved particle swarm optimization algorithm is more effective in the calculation of the power system economic dispatch problem.

\section{CONCLUSION}

In this paper, we improve the basic particle swarm optimization algorithm and obtain the 
dynamic double population particle swarm optimization algorithm. The algorithm can be divided into two second-level sub populations, and the two sub populations are studied according to different strategies. One population is used to find the optimal value of the sub population, and the other one is used to find the difference between the sub populations. All particles are studied according to the optimal learning strategy. After system simulation and analysis of the results, we can draw the following conclusions: the optimization results of the improved particle swarm algorithm are better than the optimization results of the basic particle swarm algorithm and the improved particle swarm optimization algorithm can effectively solve the power system economic dispatch calculation problem.

\section{REFERENCES}

[1] Yuan Y, Zhang X, Ju P, et al. Determination of economic dispatch of wind farm-battery energy storage system using Genetic Algorithm[J]. International Transactions on Electrical Energy Systems, 2014, 24(2):264-280..

[2] Sun J, Wu X, Palade V, et al. Random drift particle swarm optimization algorithm: convergence analysis and parameter selection [J]. Machine Learning, 2015, 101:1-32.

[3] Upadhyay P, Kar R, Mandala D, et al. Craziness based particle swarm optimization algorithm for IIR system identification problem [J]. AEU - International Journal of Electronics and Communications, 2014, 68(5):369-378.

[4] Gao Y, Li S. Improved Particle Swarm Optimization Algorithm[C]// Computational Intelligence and Software Engineering (CiSE), 2010 International Conference on. IEEE, 2010:1-4..

[5] Yang H, Yi J, Zhao J, et al. Extreme learning machine based genetic algorithm and its application in power system economic dispatch[J]. Neurocomputing, 2013, 102(2):154-162..

[6] Ting C J, Wu K C, Hao C. Particle swarm optimization algorithm for the berth allocation problem[J]. Expert Systems with Applications, 2014, 41(4):1543-1550.

[7] Zhang Z, Jiang Y, Zhang S, et al. An adaptive particle swarm optimization algorithm for reservoir operation optimization[J]. Applied Soft Computing, 2014, 18(4):167-177..

[8] Xing Qinghua, Ren Junliang, Li Qiang, et al. Anti missile early warning resource scheduling method based on adaptive probabilistic particle swarm algorithm [J]. Journal of Air Force Engineering University: Natural Science Edition, 2014, (6): 45-48.

[9] Tai-Zhi L V, Zhou W, Xia P P. Novel particle swarm optimization algorithm[J]. Application Research of Computers, 2014, (7): 43-46. 